\section{Prevention of COPD exacerbations by salmeterol/fluticasone propionate or tiotropium - the INSPIRE study}

\author{
*Alan Kaplan \\ Chair, Family Physician Airways Group of Canada \\ *Tel: +1 9058831100 \\ E-mail: for4kids@gmail.com
}

Wedzicha JA, Calverley P, Seemungal T, Hagan G, Ansari $Z$, Stockley $R$ for the INSPIRE Investigators. The prevention of chronic obstructive pulmonary disease exacerbations by salmeterol/fluticasone propionate or tiotropium bromide. Am J Respir Crit Care Med 2008; 177(1):19-26.

Exacerbations are very important factors which affect the morbidity, mortality and progression of COPD. In this study, the relative efficacy of the long-acting inhaled bronchodilator/antiinflammatory combination salmeterol/fluticasone propionate (SFC) $50 / 500 \mathrm{mcg}$ twice daily was compared to the lopgacting bronchodilator tiotropium (Tio) $18 \mathrm{mcg}$ once daily in preventing exacerbations and related outcomes in severe and very severe chronic obstructive pulmonary disease (COPD). This 2-year, double-blind, double-dummy paraltel study recruited 1323 patients with COPD (mean FEV of $39 \%$ ). The primary endpoint was health care utilisation exacerbation rate. Other endpoints included health status measured by the St. George's Respiratory Questionnaire (SGRQ), mortality, adverse events, and study withdrawal. The study was funded by GlaxoSmithKline.

Results: Exacerbation Rate: 1.28 in SFC vs 1.32 in Tio (p $=0.656)$; SGRQ: 2.1 difference over two years; Withdrawal from study: $29 \%$ higher in Tio vs SFC ( $p=0.005)$; M ortality: SFC $3 \%$ vs Tio $6 \% \quad(p=0.032)$; Pneumonia: More reported in the SFC group than Tio $(p=0.008)$.

Conclusion: Patients with severe COPD treated with SFC had a statistically significant improvement in quality of life and mortality, and had a significant decrease in withdrawals. The exacerbation rates were similar, but the SFC group had significantly more pneumonias.

\section{Comment}

At first glance, the INSPIRE study seems to show that SFC confers a decrease in mortality and improvement in quality of life, with significantly less withdrawals. This is balanced by an increase in pneumonia. The study failed to show a difference in the primary endpoint of exacerbations, however.

This study mirrors much of what was seen in the TORCH study, ${ }^{1}$ with the reduction in mortality and increase in pneumonia. The lower numbers here presumably prevent adequate power in order to see some other issues. Clearly the higher drop out rate in the Tio group may have caused more patients to end up on SFC instead, in this intention-to-treat analysis, thus decreasing the differences between the two groups. This may cause an underestimation of potential SFC effects.

The SGRQ difference is a statistical one only, with clinically meaningful changes being a four point drop. Again, perhaps a larger power would have shown this, but I cannot feel that this is clinically important.

The increase in pneumonia in patients treated with ICS mirrors work in TORCH and others. ${ }^{2,3}$ However, in INSPIRE, there is no reduction in exacerbations to balance this out. Interestingly, fewer patients assigned to SFC needed oral steroid treatment, but fewer patients assigned to Tio needed antibiotic treatment. Overall, $39 \%$ of the patients did not have a COPD exacerbation during the two-year study at all...

M y major concern relating to this study design is that these patients had severe or very severe COPD and that they should therefore have been on two long-acting bronchodilators according to all guidelines. ${ }^{4,5}$ This then leads us to make a comparison with the OPTIM AL study in which SFC was added to Tio, wherein overall exacerbation rates were again not affected, although severe exacerbations were decreased.

What further analysis do we need? This study would benefit from a review of the patients $(39 \%)$ who did not have an exacerbation at all. Are these patients biologically dissimilar? In our Canadian guidelines (Figure 1) we have divided the moderate-to-severe patients into those with or without exacerbations in an attempt to determine who gets ICS added to their treatment. This may save some patients requiring treatment with ICS with the possibility of an increased risk of pneumonia? Also, we do not know if ICS actually does benefit these patients. I believe there are indications in these studies that ICS treatment is causing a reduction in mortality, but in which patients?

All clinicians would like to know which long-acting bronchodilator to start first. Should it be the long-acting anticholinergic tiotropium or a long-acting beta-agonist (LABA) such as salmeterol or eformoterol? If the LABA, should it be in 
Figure 1. Increasing disability and lung

\section{function impairment.}

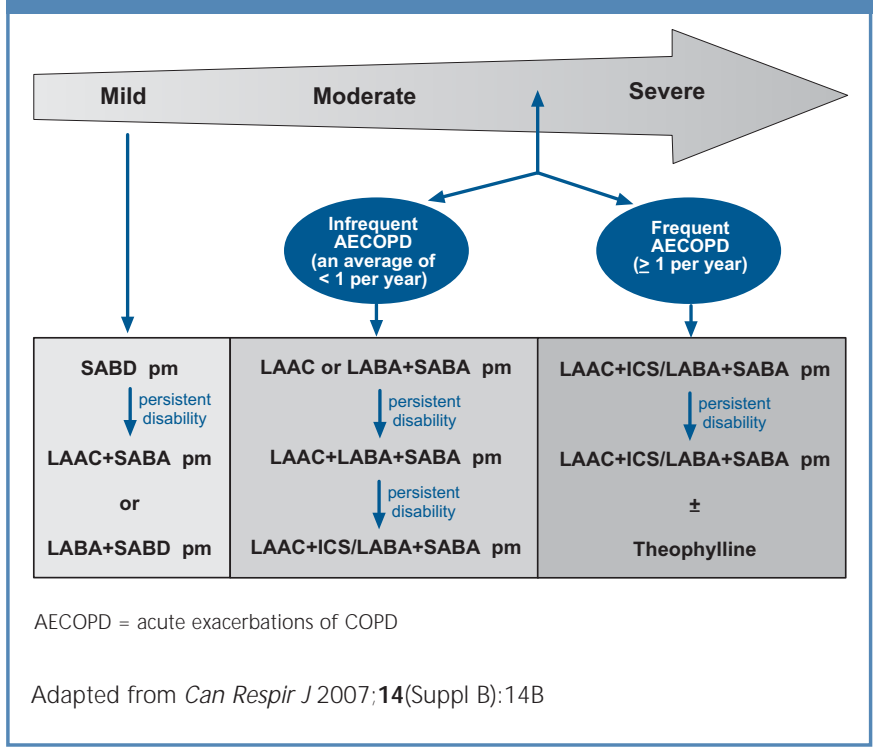

combination with an inhaled steroid? However, we are making this decision in patients with mild to moderate disease, a different population from the patient cohort in this study.

In summary, the INSPIRE study sets out to answer the question; which drug should we use first in COPD patients salmeterol/fluticasone or tiotropium? I do not think it answers the question for two reasons: firstly, this is a cohort of patients with severe COPD that should have been on both long-acting bronchodilators anyway; and secondly, it did not show a difference in the primary outcome measure, namely exacerbation rates. Nevertheless, it clearly makes a difference when one adds ICS to a LABA, with decreased mortality and an improvement in quality of life. The tough question is; which patients should have ICS in addition to their LABA? This study provides no answers.

\section{References}

1. Calverley P, Andeson J, Celli B, et al. Salmeterol and fluticasone propionate and survival in chronic obstructive lung disease. NEJM 2007:356:775-89.

2. Ernst $P$, Gonzalez A, Brassard $P$, et al. Inhaled corticosteroid use in chronic obstructive pulmonary disease and the risk of hospitalization for pneumonia Am J Respir Crit Care 2007;176:162-6

3. Sin DD, Golmohammadi K, Jacobs P. Cost-effectiveness of inhaled corticosteroids for chronic obstructive pulmonary disease according to disease severity. Am J Med 2004;116:325-31.

4. www.COPDgold.com

5. O'Donnell D, Aaron S, Bourbeau J, et al. Canadian Thoracic Society recommendations for the management of Chronic Obstructive Pulmonary disease - 2007 Update. Can Resp J 2007;14(Suppl B):5B-32B.

6. Aaron SD, Vandemheen $\mathrm{KL}$, Ferguson $\mathrm{D}$ et al. Tiotropium in combination with placebo, salmeterol, or fluticasone-salmeterol for treatment of chronic obstructive pulmonary disease. Ann Intern Med 2007;146(8):545-55.

\section{Available online at http://w w w.thepcrj.org}

